3 "Lecture on the Ethnology of the Ancient Irish." Extract from the Dublin Literary.Journal. 16 pp. Dublin, Kirkwood, pr., 1844.

4 "The Closing Years of Dean Swift's Life." Dublin, 1849. Second edition, enlarged, Dublin, 1849.

5 "The Beauties of the Boyne and the Blackwater.". Dublin, 1849. Second edition, enlarged, Dublin, 1850.

6 "Observations on the Epidemic Ophthalmia, which has prevailed in the Workhouses and Schools of the Tipperary and Athlone Unions." Reprinted from the London Journal of Medicine, Jan., 1851. 30 pp. Dublin, 1851.

7 “Irish Popular Superstitions." Dublin, 1852.

8 "Practical Observations on Aural Surgery and the Nature and Treatment of Diseases of the Ear." London, Dublin printed, 1853.

9 "On the Physical, Moral, and Social Condition of the Deaf and Dumb." London, Dublin printed, 1854.

10 “Medico-legal Observations upon Infantile Leucorrhoea." London, 1854.

11 "A Descriptive Catalogue of Stone, Earthen, Vegetable, Animal and Bronze Materials in the Museum of the Royal Irish Academy." 2 parts. Dublin, 1857-1861.

"A Descriptive Catalogue of the Antiquities of Gold in the Museum of the Royal Irish Academy." Dublin, 1862.

"An Essay on the Malformations and Congenital Diseases of the Organ of Sight." London, Dublin printed, 1862.

"Description of the Tonymore Crannog, County of Cavan." Reprinted from the Proc. of the Roy. Irish Acad. 14 pp. Dublin, 1863.

"Ireland, Past and Present : the Land and the People." Dublin, 1864. Another edition, see Dublin: Young Men's Christian Association: Lectures, 1864, etc., 1865.

16 "Lough Corrib." Dublin, 1867.

17 "Cleopatra's Needle. A Proposal Relative to the Nelson Testimonial." Printed for private circulation, 1877.

18 "Memoir of C. Beranger, and his Labours in the Cause of Irish Art and Antiquities." Dublin. H. M. Gill, 1880.

\title{
COMMUNICATIONS
}

\section{NOTES ON SIX CASES OF IRITIS AND CYCLITIS OCCURRING IN DYSENTERIC PATIENTS}

\author{
Euphan M. MaXwell, \\ F.R.C.S.I., M.B., ATTACHED R.A.M.C. \\ BY \\ AND \\ WALTER H. KIEP, \\ CAPT. R.A.M C.
}

DURING the winter of $1916-17$ we have had opportunities of seeing six cases, the subjects of infection with $B$. dysenteriae (Shiga) who developed iritis or cyclitis. All these cases were drawn from the Mediterranean area, and in four of them arthritis occurred as well. Our attention was first directed to this subject by Colonel A. E. Garrod, C.M.G., A.M.S., to whom we should like to take this opportunity of acknowledging our indebtedness.

Case 1.-Pte. W., aged 18 years. This patient reported sick with diarrhoea and the passage of blood and mucus in the stools on September 18, 1916. On September 27, 1916, i.e., on the tenth 
day of illness, he complained of stiffness in the right knee. Thereafter the right elbow and the right shoulder, and the left elbow and the left shoulder became involved, and about October 1 or 2,1916, the left knee became affected as well. On October 15, 1916, the wrists and some of the joints in the right hand were painful. On October 15 or 16,1916 , i.e., about four weeks after onset of illness, patient noticed a slight defect of vision in the right eye. He was seen by one of us on October 18,1916, when it was found there was well marked ciliary hyperaemia of the right eye, and that the right pupil did not dilate as fully as the left one when the light was screened off. A mydriatic was then introduced into the right eye, and at the end of an hour's time the pupillary ring was found considerably retracted. Examination then showed that, adherent to the anterior capsule of the lens, there were three entities:-(1) a thin membranous film of exudate occupying what had been the pupillary space. (2) A large number of minute opacities peripheral to the foregoing and consisting apparently of albuminous particles. (3) Deposits of uveal pigment arranged fringe-wise round the margin of the membrane, and also extending along three lines running radially between the margin of the membrane and the edge of the iris. At each of these three points the uveal ring of the iris was seen to form a minute papillated projection.

Patient was ordered atropin drops, and by October 22, 1916, the pupil had completely dilated. Patient passed through a severe illness, losing large quantities of blood from the bowel, but the ocular symptoms never increased in intensity. He was last seen on March 8,1917 , when only some dozen or so of opacities could be faintly discerned, adherent to the anterior capsule of the lens, and occupying the site of the original uveal pigment deposits which formed the fringe of the membranous exudate.

This patient's blood serum agglutinated the $B$. dysenteriae (Shiga) powerfully, even in a dilution of 1 in 800 , on November 8 , 1916. The whole case has been described elsewhere in detail so far as the systemic condition is concerned by Capt. G. Graham, R.A.M.C.

Case 2.-Driver S., aged 22 years. This man developed diarrhoea, with abdominal pains and the passage of mucus in the stools, on September 29, 1916. He was admitted to a General Hospital on October 5, 1916, and for the next three or four days he passed on an average four stools per diem, containing both blood and mucus. On October 10, 1916, i.e., on the twelfth day of illness, his eyes became inflamed, both simultaneously, so far as he could remember. On October 14, 1916, the right knee became painful, and three days later the left knee. During the period from October 5, 1916, to November 4, 1916, he ran a temperature of a remittentintermittent type never exceeding $102^{\circ} \mathrm{F}$., as shown on the accompanying chart. He came under our observation on November 14 , 


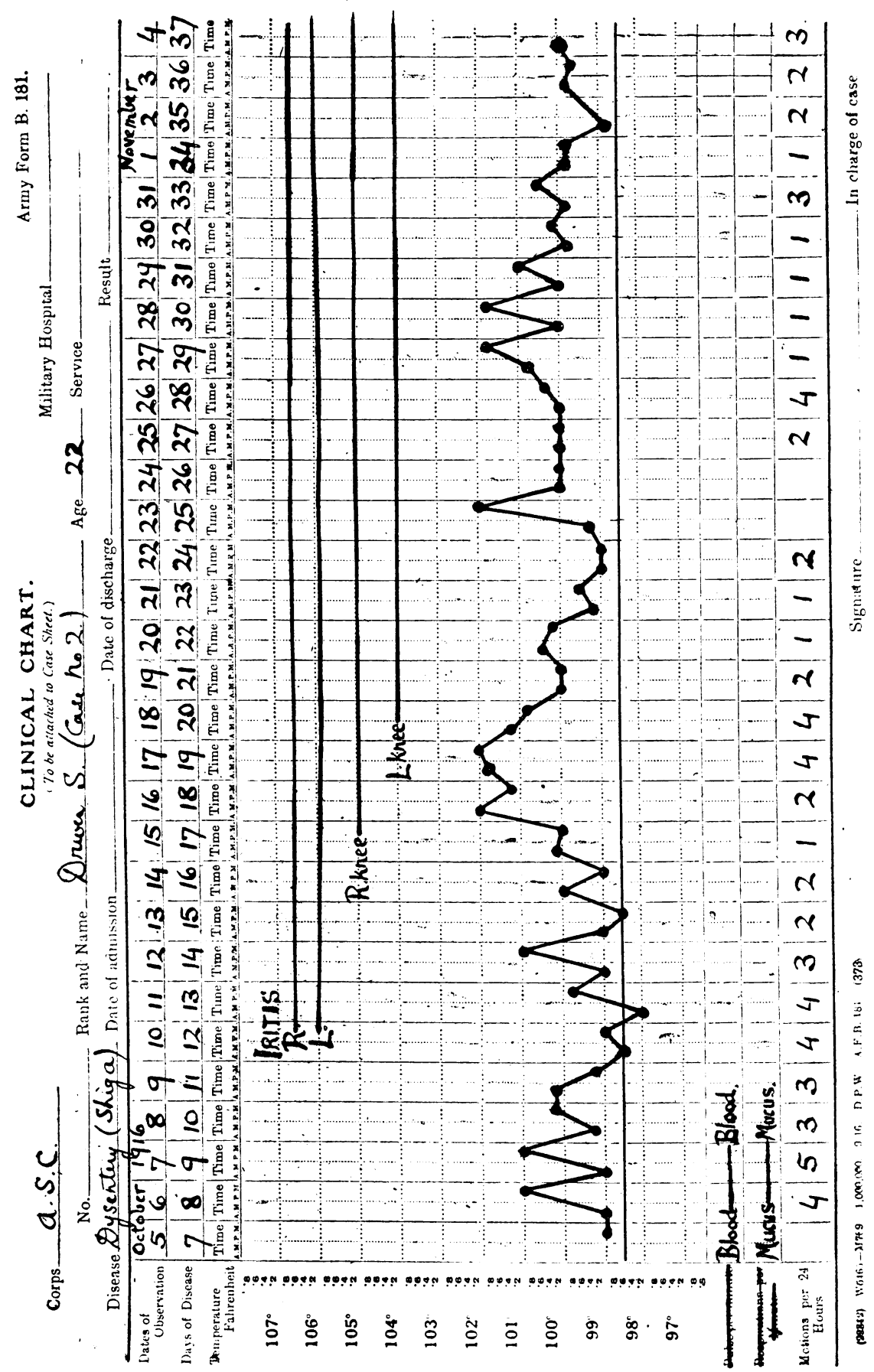


1916 , and was then found to have effusion into both knee joints, more especially the right. There was irido-cyclitis in each eye, with acute tenderness on pressure on the ciliary region, intense photophobia and considerable blepharospasm, and marked circumcorneal hyperaemia. The pupils were irregular in outline, about midway between contraction and dilatation; and the media were hazy by reason of the presence of a large number of opacities in the aqueous and vitreous. On this account fundus details were not visible in the right eye, and visible only in a blurred fashion in the left eye. The energetic use of atropin caused no further dilatation; and it was then seen that there was a complete ring-synechia in the right eye, and an almost complete one in the left eye. On November 27, 1916, the blood was sent to the bacteriologist, who reported the serum to agglutinate $B$. dysenteriae (Shiga) completely in a dilution of 1 in 200 (the dilution was not carried higher); $B$. dysenteriae $Y$ incompletely in a dilution of 1 in 50 ; and $M$. melitensis and bacilli of the enteric group not at all. On December 7, 1916, patient had pain in the right shoulder for 2 or 3 days. On December 12, 1916, the blood gave a negative Wassermann reaction. By December 17, 1916, the arthritis in the knees had subsided sufficiently to allow of patient getting up for an hour or so daily.

By December 29, 1916, the photophobia had considerably lessened, and the ciliary hyperaemia had almost vanished; by January 8,1917 , the swelling in the knees had disappeared. As patient had a complete ring-synechia in the right eye, it was thought fit to perform iridectomy, and this was done on January 18, 1917. The fragment of iris was removed with all possible aseptic precautions and transferred to a tube of bouillon for incubation. At the same time, samples of the aqueous humour and blood serum were also obtained. The laboratory investigations of this case were undertaken by Captain J. Arkwright, R.A.M.C., for whose kindness we should like to make our acknowledgments. He found that:(1) The culture of iris yielded Gram-positive cocci, viz., staphylococci and streptococci ; (2) The aqueous agglutinated $B$. dysenteriae (Shiga) ++ in a 1 in 80 dilution and + in a 1 in 160 dilution, whilst it did not agglutinate $B$. dysenteriae $Y$ at all in 1 in 20 dilution, and $B$. typhosus only + in 1 in 20 dilution, and not at all in higher dilutions; (3) The blood serum agglutinated Shiga's bacillus ++ in 1 in 400 dilution; Bacillus $Y$ not at all in 1 in 100 dilution, B. paratyphosi $A$. and $B$. not at all in 1 in 100 dilution, and B. typhosus + in 1 in 100 dilution. Patient had had inoculation against B.typhosus in October, 1915, but, so far as we could ascertain, had not been inoculated against $B$. paratyphosus $A$. or $B$.

So far as we could ascertain, this patient suffered from an infection with $B$. dysenteriae (Shiga), and no other. In the first place, there was no evidence to show that he suffered from any other infection 
that was likely to produce the syndrome of arthritis plus bilateral irido-cyclitis. So far as gonorrhoea was concerned, there was a negative history and no sign of urethritis or other affection of the genito-urinary tract during the four months that he was under observation. In the second place, we excluded the following conditions that might have caused a uveitis. There was no history of syphilis and a negative Wassermann reaction was obtained. With regard to malaria, the evidence against his suffering from this infection is as follows:- (1) In spite of the fact that he was given no quinine from the time that he came under our observation up to the date of discharge, a period of four months in all, he never developed a malarial rise of temperature, even after operation; (2) Before he reached us, viz., from the 7th to the 37 th day of illness, he was given quinine, apparently as a routine procedure, yet this does not seem to have influenced in the least the pyrexia from which he was suffering (V. chart). Finally, so far as we could ascertain, patient never had any anti-dysenteric serum, so that such a factor could not have played any part in the production of the arthritis.

Case 3.-G., aged 27. This patient reported sick with diarrhoea on October 27, 1916, when he passed ten stools per diem, containing mucus but no blood. He was admitted to Hospital next day (October 28) and the faeces were examined forthwith and found to yield $B$. dysenteriae (Shiga). He passed five or six stools on October 28 and on October 29, but by November 1 the number of stools was one only, and from that time on the bowels moved normally. $\mathrm{He}$ was given anti-dysenteric serum on November 1, 1916, and again on November 2, 1916 . By November 5, 1916, he felt so well that he went for a walk, and covered two or three miles on foot. When he reached Hospital in the evening he felt his right knee very stiff (10th day of illness). Then on November 11, 1916, he was admitted to Hospital at this Station. He was found to have a well-marked arthritis of right knee, accompanied by severe pain, and was given another dose of anti-dysenteric serum (20 c.c.). On November 17, 1916 (i.e., 22 day of illness) the left knee and right ankle became involved, and on November 19 he had a rise of temperature to $102 \cdot 2^{\circ} \mathrm{F}$., but the temperature reached normal two days later, and with one exception, noted further on, it did not go beyond $99^{\circ} \mathrm{F}$. On December 1 , 1916 (i.e., on the 36th day of illness) the right eye became inflamed. There was intense ciliary and episcleral hyperaemia; acute tenderness on the slightest pressure being applied anywhere in the region of the ciliary body, and photophobia so severe that he could not bear to open the left eye, which was in no way affected, even in dull light. Ophthalmoscopy was consequently quite out of the question, but at a later date numerous tiny punctate opacites were found in the right vitreous. Intra-ocular pressure, 
so far as could be estimated digitally, was normal in each eye. There was an obstinate tendency of the right pupil to contract down, even under atropin, but otherwise there was no sign of involvement of the iris. In spite of energetic treatment with atropin, hot fomentations, leeching at the right temple, and the free use of aspirin, patient remained much in the same condition until December 12, 1916, when it was decided to give anti-dysenteric serum (Shiga), and 20 c.c. were accordingly administered hypodermically. The effect which followed was comparable to that which occurs in a case of diphtheria after the administration of anti-diphtheritic serum. That is to say, the pain, which had been severe, became slight on the following day, and was completely absent within forty-eight hours; the pupil dilated more fully, and reached a state of maximum dilatation three days later; and the circumcorneal hyperaemia diminished steadily and was completely gone within seventy-two hours. On December 15 (i.e., three days after administration of serum) the right vitreous was searched, and numerous minute opacities were discovered in the region of the ciliary body, but no opacities were found on the anterior lens capsule or elsewhere in the aqueous, and the uveal ring was normal. On this date patient opened the left eye for the first time since the right eye had become inflamed. From this time on the right eye made an uninterrupted recovery. On December 24, 1916, the media were still slightly hazy (fundus normal); but by January 1, 1917, the media of the right eye were found to be as clear as those of the left, and all fundus details were normal. Patient suffered from serum sickness on December 18, 1916 (six days after getting serum) viz., his temperature rose to $101.8^{\circ} \mathrm{F}$; 作 had a generalized urticarial and erythematous eruption, and pain in right shoulder and right metacarpo-phalangeal joint of thumb, but this syndrome lasted for twelve hours only. A blood-culture was taken on December 19, 1916, without any result.

There was a history of gonorrhoea in this case, occurring more than two years previously; orchitis occurred, but there was no ensuing gleet; also a history of septicaemia about twelve years previously (groin-abscess, and whitlows in all his fingers and all his toes).

Case 4.--Private W., aged 45. This patient reported sick with diarrhoea on November 1, 1916. Blood and mucus were passed in the stools, which were so frequent that patient lost count of them. On December 1, 1916, there was a sudden onset of dimness of vision in each eye, which rapidly increased, so that on December 4, 1916, when he first came under our observation, he could only count fingers at a distance of less than one metre. Both pupils were seen to be irregular and to react sluggishly to light, and the intra-ocular pressure was found to be equal to $15 \mathrm{~mm}$. of $\mathrm{Hg}$. as 


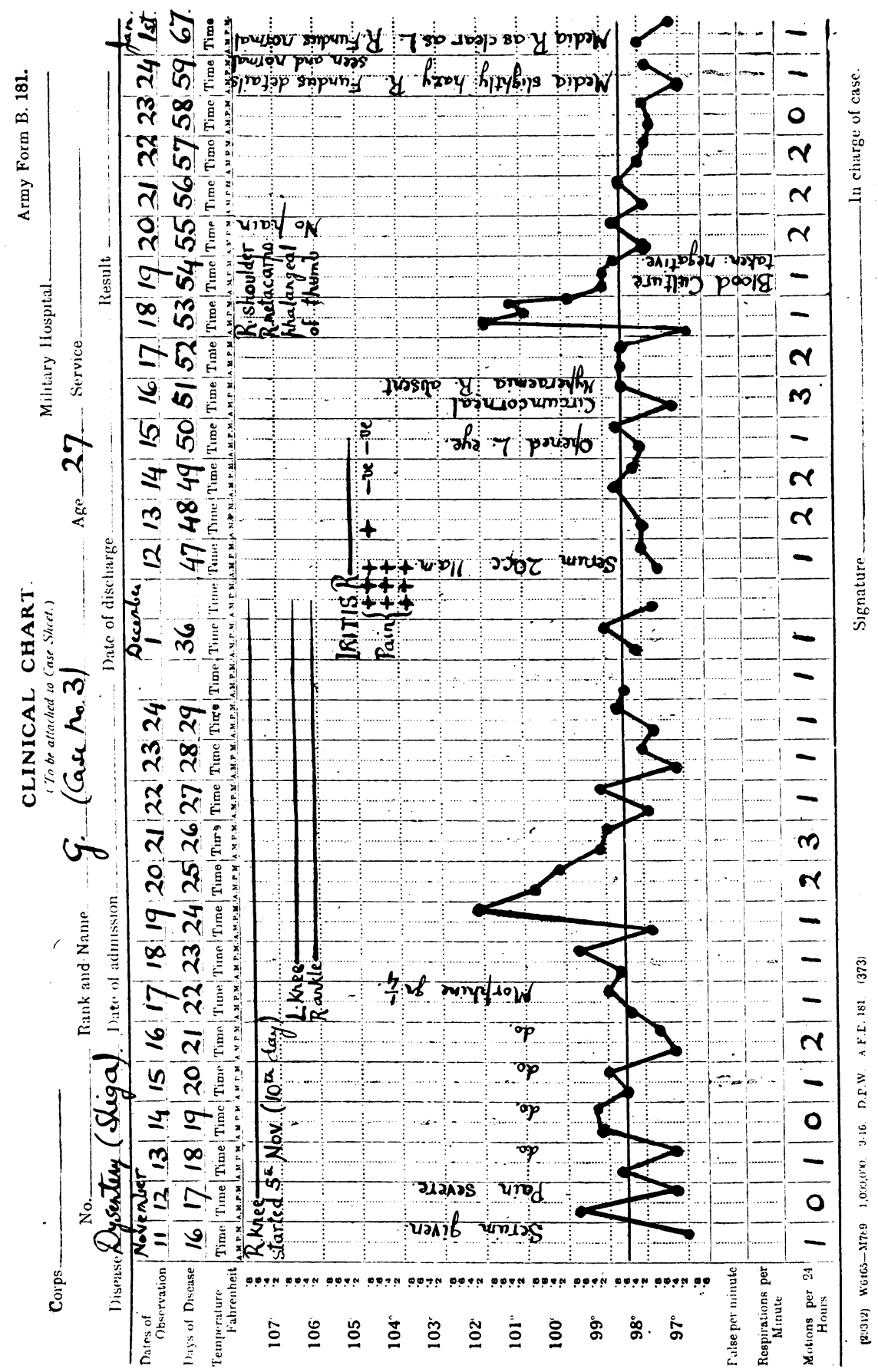


estimated by the Schiötz tonometer. The pupils dilated fully under the influence of atropin within 24 hours, and it was then found that there were deposits of uveal pigment on the anterior lens-capsule in each eye, and also numerous minute opacities dotted all over the anterior surface of the lens-capsules. Patient improved steadily and was able to read $6 / 9$ with right eye with the aid of -1.5 D.S. combined with -1.5 D.C. axis $15^{\circ}$ down and out; and $6 / 9$ with left eye with the aid of -1.5 D.S. combined with -1 D.C. axis horizontal, on January 15,1917. This patient gave no history of arthritis, nor did he develop any joint affection while under our observation. The blood-serum was found to agglutinate $B$. dysenteriae (Shiga) powerfully in a dilution of 1 in 50 , but no other dysentery bacillus at all on December 7, 1916; and on March 12, 1917 , a second examination showed the serum to agglutinate Shiga's B, in a dilution of 1 in 100 but no other dysentery bacillus at all. History and evidence of gonorrhoea in this case were negative.

Case 5.-Pte. L., aged 29 years. This man contracted dysentery at the end of November, 1916. About a month later (on December $29,1916)$ his eyes became inflamed. He came under our observation on January 2, 1917, when he was found to have marked ciliary congestion right and left, and tenderness on pressure in right ciliary region. With the ophthalmosoope dust-like opacities were seen in the vitreous in the neighbourhood of the ciliary body in each eye, and the fundi were normal. Atropin was ordered but the pupils would not remain dilated with instillations thrice daily, and it was found necessary to introduce the drops six or seven times per diem in order to maintain dilatation. By January 25, 1917, the eyes presented a normal appearance. The circumcorneal hyperaemia had vanished; the media were clear; and there was no tenderness on pressure on the ciliary regions. This patient's blood serum agglutinated Shiga's. B. ++ in a 1 in 160 dilution, and + in a 1 in 320 dilution; B. dysenteriae $Y+$ in a 1 in 80 dilution; and Flexner's B. of dysentery + in a 1 in 160 dilution. By the bacteriologist he was pronounced to be an unequivocal case of infection by $B$. dysenteriae (Shiga).

Case 6.-Pte. Sh., aged 22 years. This patient developed "rheumatism" in right ankle on October 14, 1916. The right knee became involved on October 15, 1916 ; the right eye on October 16, 1916 ; the right shoulder on October 18, 1916, and the left eye about November 6, 1916. He gave no history of dysentery, but nevertheless his blood-serum agglutinated $B$. dysenteriae (Shiga) in a dilution of 1 in 800 on January 3,1917 . He admitted that he had had diarrhoea, but that it was so slight that he had paid no attention to it. On the other hand, it should be noted that the faeces were cultivated three times between January 1, 1917, and January 24, 1917, and 
yielded negative results each time. There was no history of gonorrhoea, and no evidence of involvement of the genito-urinary tract. Patient had posterior synechiae and deposits of uveal pigment on the anterior lens-capsule of each eye. There was no history of "rheumatism" having ever occurred in his life before, and there was no evidence of his having had malaria.

\section{Conclusions.}

(1) Patients suffering from an infection by $B$. dysenteriae (Shiga) may occasionally develop anterior uveitis as a result of this infection, as pointed out by Morax ${ }^{1}$.

(2) This ocular affection may, or may not, be accompanied by articular manifestations.

(3) The ocular affections would appear to occur most frequently about one calendar month after the first signs of involvement of the bowel, but may occur as early as the twelfth day (Case 2).

(4) The articulo-ocular syndrome corresponds exactly to that occurring in another affection of a mucous tract, viz., gonorrhoea, as pointed out by Garrod.

\section{A CASE OF SIDEROSIS AFFECTING THE INNER- VATION OF THE PUPIL}

BY

IVor Ll. Tuckett, M.D. Cantab.

Dilatation of the pupil following siderosis has been noted before; and Vossius, in a paper on Siderosis Bulbi, read before the Heidelberg Ophthalmological Society in August, 1901 (see Ophthalmic Review, Vol. XXI, p. 223), ascribed the dilation of the pupil to a chemical irritation of the sympathetic fibres in the iris. But the following case (which was treated at the Royal London Ophthalmic Hospital, while I was House Surgeon and temporary Curator in 1917, under the care of Mr. J. Herbert Parsons, who has kindly given me permission to publish my observations) appears to show that iron salts injure the endings of the 3rd nerve in the iris rather than stimulate those of the sympathetic; and that the dilatation is due to the prevention of constrictor impulses reaching the iris through the 3rd nerve. Indeed, in this case I have found that the sympathetic nerve endings are injured by iron salts quite as much as those of the 3rd nerve, and that the dilatator pupillae loses its function; so much so that some time after removal of the piece of

1. British Jl. of Ophthal., March, 1917, pp. 186. 